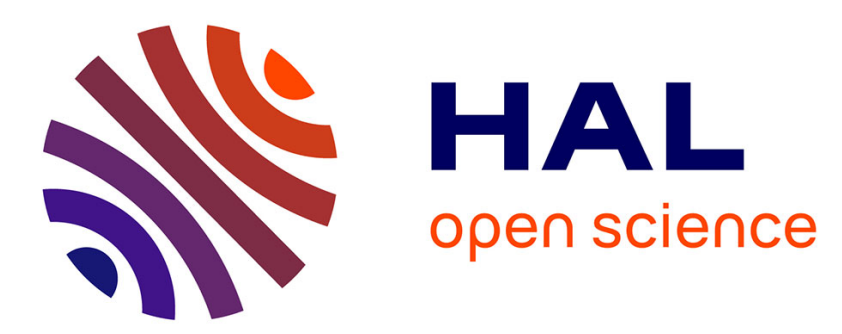

\title{
Free-breathing 3D diffusion MRI for high-resolution hepatic metastasis characterization in small animals
}

Emeline Ribot, Aurélien Trotier, Charles Castets, Benjamin Dallaudière, Eric Thiaudière, Jean-Michel Franconi, Sylvain Miraux

\section{- To cite this version:}

Emeline Ribot, Aurélien Trotier, Charles Castets, Benjamin Dallaudière, Eric Thiaudière, et al.. Freebreathing 3D diffusion MRI for high-resolution hepatic metastasis characterization in small animals. Clinical and Experimental Metastasis, 2016, 33 (2), pp.167-178. 10.1007/s10585-015-9766-6 . hal02404816

\section{HAL Id: hal-02404816 \\ https://cnrs.hal.science/hal-02404816}

Submitted on 18 Feb 2020

HAL is a multi-disciplinary open access archive for the deposit and dissemination of scientific research documents, whether they are published or not. The documents may come from teaching and research institutions in France or abroad, or from public or private research centers.
L'archive ouverte pluridisciplinaire HAL, est destinée au dépôt et à la diffusion de documents scientifiques de niveau recherche, publiés ou non, émanant des établissements d'enseignement et de recherche français ou étrangers, des laboratoires publics ou privés. 


\section{Free-breathing 3D diffusion MRI for high-resolution hepatic metastasis characterization in small animals}

Emeline J Ribot ${ }^{1}$, Aurélien J Trotier ${ }^{1}$, Charles R Castets ${ }^{1}$, Benjamin Dallaudière ${ }^{1}$, Eric Thiaudière ${ }^{1}$, Jean-Michel Franconi ${ }^{1}$, Sylvain Miraux ${ }^{1}$

1 Centre de Résonance Magnétique des Systèmes Biologiques, UMR 5536, CNRS/ University Bordeaux

Corresponding author: Emeline Julie Ribot

Centre de Résonance Magnétique des Systèmes Biologiques

UMR 5536, CNRS/University Bordeaux

146 rue Léo Saignat, 33076 Bordeaux

Email: ribot@ rmsb.u-bordeaux2.fr

Short Title : 3D DW-MRI of hepatic metastases in mice at 7T

Keywords : diffusion, metastasis, liver, mouse, 7T, 3D MRI

Article Type : Research paper 


\begin{abstract}
The goal of this study was to develop a 3D diffusion weighted sequence for free breathing liver imaging in small animals at high magnetic field. Hepatic metastases were detected and the Apparent Diffusion Coefficients (ADC) were measured.
\end{abstract}

A 3D SE-EPI sequence was developed by (i) inserting a water-selective excitation radiofrequency pulse to suppress adipose tissue signal and (ii) bipolar diffusion gradients to decrease the sensitivity to respiration motion. Mice with hepatic metastases were imaged at $7 \mathrm{~T}$ by applying $\mathrm{b}$ values from 200 to $1100 \mathrm{~s} / \mathrm{mm}^{2}$. 3D images with high spatial resolution $(182 \times 156 \times 125 \mu \mathrm{m})$ were obtained in only $8 \min 32 \mathrm{~s}$.

The modified DW-SE-EPI sequence allowed to obtain 3D abdominal images of healthy mice with-fat SNR 2.5 times lower than without any fat suppression method and sharpness 2.8 times higher than on respiration-triggered images. Due to the high spatial resolution, the core and the periphery of disseminated hepatic metastases were differentiated at high b-values only, demonstrating the presence of edema and proliferating cells (with ADC of 2.65 and $1.55 \mathrm{~mm}^{2} / \mathrm{s}$, respectively). Furthermore, these metastases were accurately distinguished from proliferating ones within the same animal at high b-values (mean ADC of $0,38 \mathrm{~mm}^{2} / \mathrm{s}$ ). Metastases of less than $1.7 \mathrm{~mm}^{3}$ diameter were detected.

The new 3D SE-EPI sequence enabled to obtain diffusion information within liver metastases. In addition of intra-metastasis heterogeneity, differences in diffusion were measured between metastases within an animal. This sequence could be used to obtain diffusion information at high magnetic field. 


\section{INTRODUCTION}

Cancer is one of the leading causes of death mainly due to metastases coming from the spread of cancer cells into the whole body. The five-year survival rates of patients treated for colorectal or melanoma cancers who develop metastases are less than $13 \%$ and $17 \%$, respectively. The most common sites of developing metastases are bones, liver, lungs and brain. To detect metastases in clinics, diffusion-weighted (DW) Spin-Echo Echo Planar (SEEPI) sequence with the Stejskal-Tanner model is commonly performed on the whole body of patients. Diffusion MRI allows obtaining functional information on tumors, including the physiological states (cell proliferation/density [1,2], apoptosis [3], necrosis [4]), the stages/ grades $[5,6])$ and responses to treatments. Indeed, diffusion MRI has been shown to be an earlier biomarker compared to tumor volume $[7,8]$.

To obtain such information in humans, images are acquired in 2D usually during a breath hold [9]. However, the low spatial resolution needed in order to shorten acquisition time prevents the early detection of metastases and the study of heterogeneity within each tumors. In small animal models, this issue is accentuated as high spatial resolution is necessary. Thus, there is a need to obtain $3 \mathrm{D}$ diffusion information with high spatial resolutions. Scanning at high and ultra-high magnetic field enables to increase signal-to-noise ratio (SNR). Meanwhile, the quality of EPI images decreases due to worsen susceptibility effects generating distortion artifacts. Thus single-shot EPI can be difficult to apply, even more on areas affected by respiration motion. Consequently, most of small animal diffusion imaging was performed on immobilized parts of the body: either on brains maintained in a stereotaxic frame or on subcutaneous tumors implanted in the limbs of the animals or on bone metastases. To further minimize motion effect, respiratory-triggered acquisitions or navigator echoes were essentially performed necessitating long acquisition time [10-15]. 
Another important issue for diffusion imaging is the short $\mathrm{T} 1$ of adipose tissue. This leads to hyperintense artifacts on the EPI images acquired with long TR. Even if this artifact is not a major issue for brain imaging, it is essential to suppress fat signal for diffusion abdominal imaging. Padhani et al recommended to optimize fat suppression for DW-MRI in order to prevent ghosting artifacts by considering water-resonance frequency selective excitation [16]. However, they underline the challenges of obtaining high-quality diffusion images at high magnetic field.

Our study aimed at designing a 3D diffusion-weighted sequence at high magnetic field in order to obtain routine high-quality diffusion images of small animal abdomens. In the context of cancer, this would help improving the diagnosis and prognosis of metastases. For this purpose, a 3D SE-EPI sequence was developed by inserting (i) a water-selective excitation radiofrequency (RF) pulse to suppress adipose tissue signal and (ii) bipolar diffusion gradients to reduce the sensitivity to respiration motion. As a proof of concept, this sequence was used at high magnetic field (7T) on the upper abdomen of healthy mice. Then, the sequence was applied on a mouse model of liver metastases in order to evaluate its efficiency to obtain functional information on small tumors within a moving organ. 


\section{MATERIALS and METHODS}

\section{Cell culture}

Murine melanoma cells (B16F10) were cultured in DMEM (Dulbecco's Modified Eagle's Medium, Invitrogen) containing $10 \% \mathrm{FBS}$ (fetal bovine serum) at $37^{\circ} \mathrm{C}$ and $5 \% \mathrm{CO}_{2}$.

\section{Animal Models}

C57/B16 mice (8 weeks old, Charles River, France) were used in this study. The first group $(\mathrm{N}=12$, called « healthy mice » thereafter) didn’t undergo any surgery. A second experimental group $(\mathrm{N}=6)$ received a mesenteric injection of $2 \times 10^{5}$ B16F10 cells in $100 \mu \mathrm{L}$ DMEM, as previously described [17]. Briefly, a small incision was made along the midline of the low abdomen to expose the intestines. A large vein found in the mesentery was used to inject the cancer cells.

All experimental procedures were approved by the Animal Care and Use Institutional ethics committee of Bordeaux, France (approval n5012032-A).

\section{MR material}

The experiments were carried out on a horizontal 7T Bruker Biospec 70/20 magnet (Ettlingen, Germany), equipped with a $12 \mathrm{~cm}$ gradient insert capable of $660 \mathrm{mT} / \mathrm{m}$ maximum strength and $110 \mu$ s rise time. A volume resonator (75.4 $\mathrm{mm}$ inner diameter, active length $70 \mathrm{~mm}$ ) operating in quadrature mode was used for transmission. Abdominal imaging was performed using a $4(2 \times 2)$ phased-array receive surface coil (outer dimensions of one coil element: $20 \times 18 \mathrm{~mm}^{2}$; total outer dimensions: $35 \times 32 \mathrm{~mm}^{2}$ ). 
Mice were anesthetized with $1.5 \%$ isoflurane in air during the imaging session. Mouse respiration was monitored during the entire experiment using an air balloon placed on the abdomen of the mice (SA Instruments Inc., NY, USA).

\section{MR sequence}

A conventional 2D diffusion-weighted SE-EPI sequence with the Stejskal-Tanner model was used. It was then modified to obtain a 3D sequence (noted « Native » thereafter) by inserting a slice encoding gradient. Then, the sequence was divided into three modules: the waterselective excitation module, the diffusion module and the EPI acceleration module (Figure 1).

To specifically excite water protons but not fat protons, the single $90^{\circ} \mathrm{RF}$ pulse was replaced by a water frequency-selective binomial pulse (containing 5 square sub-pulses and noted «WS » thereafter), as previously described [18]. Each pulse lasted $150 \mu$ s, the interpulse delay was set to $200 \mu \mathrm{s}$, the intensities of the pulses followed the schematic 122321 (see Supplementary Figure 1). The slice selection gradient was removed. This method was compared to a common Fat Suppression module (composed of a $90^{\circ}$ saturation RF pulse, set as default by the vendor and noted « FatSat» thereafter) on $b=100 \mathrm{~s} / \mathrm{mm}^{2}$ images.

The diffusion module was composed of two inverse-intensity bipolar gradients placed on each side of the $180^{\circ} \mathrm{RF}$ pulse (noted «Bipolar» thereafter) [19]. In that case, the duration of the gradients $(\delta)$ was $3.5 \mathrm{~ms}$. To compare with the standard method at $600 \mathrm{~s} / \mathrm{mm}^{2}$, monopolar gradients combined with respiration triggering were used. In that latter case, $\delta=3.5 \mathrm{~ms}$ and the delay between each gradient $(\Delta)$ was $5.9 \mathrm{~ms}$.

Finally, the acceleration module was composed of a train of echoes. In this study, 48 echoes, corresponding to a division of the k-space into 4 interleaved segments, were recorded per TR. 
At 7T, susceptibility effects are important, leading to distortions in the images acquired using single-shot EPI. However, by segmenting the k-space into at least 4 segments (reducing TE from $91.9 \mathrm{~ms}$ to $31.7 \mathrm{~ms}$ ), distortions were no more present, even though acquisition time was consequently increased.

To prevent ghosting artifacts, an automatic ghost correction set by the vendor was applied before every scan. This correction consisted in a linear phase correction for the Nyquist ghost suppression.

The other sequence parameters are reported in Table 1. Bipolar diffusion gradients were used when mentioned, otherwise monopolar gradients were used. In this study, the diffusion gradients were implemented in the phase direction only, as metastases and tumors typically grow in a disorganized fashion, inducing isotropic diffusion [20,21]. Increasing b values $(0$; $200 ; 400 ; 600 ; 800 ; 1000 ; 1100 \mathrm{~s} / \mathrm{mm}^{2}$ ) were applied by increasing the intensity of the diffusion gradients, while maintaining their durations to $3.5 \mathrm{~ms} \mathrm{[22].}$

\section{Histology}

Mice were sacrificed at the end of the MRI sessions through a 4\%-paraformaldehyde perfusion. Livers were removed and frozen, then cut into $16 \mu \mathrm{m}$-thick slices using a cryostat. Haematoxylin and Eosin stains were performed on 80 slices, each of them were separated by $64 \mu \mathrm{m}$. The metastases were easily detected by visual inspection since they appeared black due to their melanin content. The analyses were performed by a single observer (EJR).

\section{Image Analysis}


Igor Pro (Wavemetrics, Lake Oswego, OR) data processing software was used to calculate the SNR of adipose tissue and muscles. A region of interest (ROI) was drawn within subcutaneous fat or back muscles. SNR was defined as the signal intensity of ROI divided by the standard deviation of the noise (measured from a large ROI positioned outside of the mouse body in the axial plane).

To measure the relative N/2-ghost intensity (RGI), a ROI was drawn in a region where N/2 ghost was present and in the corresponding area on the parent image. RGI is the percentage of the ghost signal compared to the parent signal intensity (similarly to the methods described by Buonocore et al [23]): RGI= (Sghost/Sparent) x 100 .

Sharpness of the images acquired under different conditions (respiration triggering or not, implementation of monopolar or bipolar gradients) was assessed. For this purpose, the images were interpolated to increase the number of pixels in the readout and the phase dimensions, from 192 to 1152 and from 128 to 768, respectively. A signal intensity profile was measured across the kidney and the fat. Image sharpness $\left(\mathrm{mm}^{-1}\right)$ was calculated from the distance between $80 \%$ and $20 \%$ of the maximum and minimum signal values, as previously described by Larson et al [24].

The Apparent Diffusion Coefficient (ADC) was measured on the hepatic metastases. For this purpose, SNR of the core, the periphery or the entire metastasis were measured in function of b values higher than $200 \mathrm{~s} / \mathrm{mm}^{2}$ in order to avoid perfusion effect. To do so, the same ROI within the core, the periphery or the one delineating the whole metastasis were used for all the images acquired with different $b$ values. The linear decay of the points $\ln (\mathrm{SNR})$ in function of $\mathrm{b}$ values was used to determine the ADC value.

Two independent readers (one was a radiologist expert in MR imaging, the other was an MR scientist) qualitatively evaluated the Native, FatSat+Trig, WS+Trig and WS+Bipolar 
sequences in a blinded fashion. The readers rated the sequences using a 5-point scale (1, worst; 5, best) with respect to the presence of fat signal, motion artifacts and ghosting artifact and the extent to which such artifacts interfered with the diagnosability of the images. Finally, they were asked about the overall suitability of the sequences for abdominal DW imaging. They evaluated four sets of independent images and the scores were averaged.

\section{Statistical Analysis}

All values are expressed as mean \pm standard deviation. Paired Student $\mathrm{t}$-tests were conducted using IgoPro Wavemetrics Statistical tool box. A p-value inferior to 0.05 was considered significant. 


\section{RESULTS}

\section{D abdominal diffusion imaging on healthy mice}

\section{- Fat suppression module}

In order to evaluate the efficiency of the water frequency-selective binomial pulse, abdominal diffusion imaging was performed (Figure 2). By applying a Fat Saturation module, fat signal was largely decreased but some remaining adipose tissue with SNR of $7 \pm 0.5$ could be detected at the edges of the FOV (Figure 2a,b, arrow). Furthermore, due to low field homogeneity at the mouse abdomen level at high magnetic field, some water protons were also saturated inducing a lack of signal at the top of the image (Figure 2a arrowhead). By using the frequency-selective binomial pulse, fat SNR was 2.5 times lower than on images acquired without any fat suppression module (Table 2). Furthermore, compared to images acquired with the Fat Saturation module, fat protons were no longer excited on the entire whole 3D images, as shown in Figure 2c,d.

\section{- Respiration motion sensitivity}

The influence of respiration motion was then studied on the WS images. Without any motion correction technique, the abdominal native diffusion images showed a really low quality (Figure 3a, d). Triggering the acquisition with the respiration allowed to obtain higher quality but still blurry images (Figure 3b, e arrow). Finally, when bipolar gradients were inserted without respiration triggering, the diffusion images allowed to accurately delineate the kidneys from the back muscles, the medulla from the cortex and their irrigating vessels (Figure 3c, f).

These observations were confirmed by quantifying the sharpness of the images (Table 2). The sharpness of native abdominal diffusion images increased by a factor of 4 when respiration 
triggering was employed. By implementing bipolar gradients within the sequence, images became 11-times sharper. In parallel, the standard deviation of the noise was largely decreased when bipolar gradients were applied compared to the respiration triggering method. It is worth mentioning that triggering the acquisition with the respiration while using bipolar gradients didn't lead to significant improvements in image quality $(\mathrm{p}=0.21)$ but acquisition time was increased by $\approx 20 \%$. Furthermore, even if the echo time was increased due to the insertion of bipolar diffusion gradients, no susceptibility artifacts were observed.

Concerning ghosting artifacts that are a major concern in diffusion MRI, a standard correction was used for all the sequences. Consequently, no difference in relative ghost signal intensity was measured between all the sequences that were used in this study, except for the Native sequence (Table 2).

Two readers rated the robustness of the new WS+Bipolar DW sequence (Table 3). The results showed that the quality of the images are significantly better than the others, in term of suppressing fat signal over the entire FOV, decreasing the sensitivity to respiration motion and decreasing the appearance of ghosts. Finally, the diagnosability of the WS+Bipolar images were rated significantly higher.

The new sequence allowed to obtain 3D diffusion abdominal images without fat signal or motion artifact on healthy mice. High $b$ values of $1100 \mathrm{~s} / \mathrm{mm}^{2}$ could then be reached (Figure 4), without decreasing the quality of the images. The sharpness of the abdominal images was similar for all the b values tested (data not shown).

\section{D liver metastasis diffusion imaging}


The ability of the new 3D sequence to detect small metastases in motion-affected areas was evaluated within the liver (Figure 5).

As soon as hepatic metastases were detected by T2-like weighted imaging [25], diffusion imaging was applied. All the metastases detected on T2-like weighted images were detected on the diffusion images. Metastases of less than $1.7 \mathrm{~mm}^{3}$ were detected as hyperintense areas compared to liver on images acquired at low b-values. One would note some artifacts at the lung level, that might be due to respiration motion and high heterogeneities in the magnetic field at this precise location. However, areas of the body located lower than the chest were not affected by these artifacts. At higher $b$ values, the internal structures of the metastases were distinguished, whereas metastases appeared homogeneous at low b values. In most of them, the core was detected as hypointense areas whereas the edge of the tumor was in hypersignal on high b-value images (Figure 5a,b,c). The Apparent Diffusion Coefficient (ADC) was measured (Table 4), confirming a significantly higher diffusivity in the core than at the periphery $\left(2.65 \pm 0.15 \mu \mathrm{m}^{2} / \mathrm{ms} \quad\left(\mathrm{R}^{2}=0.99\right)\right.$ and $1.55 \pm 0.12 \mu \mathrm{m}^{2} / \mathrm{ms}^{2} \quad\left(\mathrm{R}^{2}=0.98\right)$, respectively $(\mathrm{p}=0.001))$. In comparison, the ADC of healthy parts of the liver was $8.06 \pm 1.3 \times 10^{-3} \mu \mathrm{m}^{2} / \mathrm{ms}$ $\left(\mathrm{R}^{2}=0.9\right)$. Histology performed on these metastases demonstrated that the cores mainly contained large empty spaces, certainly full of free water in vivo like edemas, whereas high density proliferating cancer cells were located at the edges of the metastases (Figure 6a,b).

The new developed 3D sequence also allowed to obtain functional information in different metastases within a same animal. Supplementary Table 1 shows the ADC of 20 metastases detected in several mice. Large differences in diffusivity could be measured. Figure 5d,e,f displays an example of two typical metastases: metastases 1 whose signal decreased on high b-values images and metastases 2 with a maintained hypersignal even when intense diffusion gradients were applied. This lead to significantly different ADC values of $1.17 \pm 0.08 \mu \mathrm{m}^{2} / \mathrm{ms}$ 
$\left(\mathrm{R}^{2}=0.98\right)$ and $0.38 \pm 0.06 \mu \mathrm{m}^{2} / \mathrm{ms}\left(\mathrm{R}^{2}=0.91\right)$, respectively $(\mathrm{p}=0.028$; Table 4$)$. As mentioned above, this correlated with large edemas within some metastases whereas dense cellularity was mainly observed in others, as detected by histology (Figure 6c,d). It has to be noted that the ADC were not correlated with the volumes of the metastases (data not shown). 


\section{DISCUSSION}

This paper focused on the development of a 3D diffusion-weighted MR sequence in order to perform diffusion imaging on any part of the small animal body at high magnetic field. Previous studies developed 3D DW sequences to image mouse brains. In order to obtain highresolution images, stereotaxic frames had to be employed to minimize motion and navigatorecho correction was used. Our study reveals high-resolution DW imaging can be obtained without the need to tie animals in specific frames or to apply any correction. As a proof-ofconcept, imaging of abdomen was focused on because this area is affected by respiration motion, possesses a wide variation in field homogeneity and contains much adipose tissue. For this purpose, a water frequency-selective excitation was inserted into a 3D SE-EPI sequence to prevent any ghosting artifacts on the images. This method has been shown to efficiently suppress fat signal from the images, without increasing significantly the echo time and acquisition time or restricting TE/TR values compared to other fat suppression methods [26]. Furthermore, contrarily to a default suppression module, fat signal was efficiently minimized on entire large FOVs even in areas with low magnetic field homogeneities. Even though this excitation pulse was not spatially selective, spinal cord imaging was performed through a restricted FOV $(1.5 \mathrm{~mm}$ in the RL direction) without any overlap or ghost artifacts (data not shown). This demonstrates the ability of the modified sequence to perform wholebody diffusion imaging and to obtain functional information also on small FOV of interest.

Very few studies attempted to perform diffusion imaging at high magnetic field on smallanimal moving organs, like the liver. Mouse liver fibrosis was studied at $7 \mathrm{~T}[27,28]$ and at 9.4T [29] using 2D DW SE-EPI with respiration triggering. Lee et al applied a similar sequence using respiration gating to detect clusters of metastases from ovarian cancer in the mouse abdomen at $4.7 \mathrm{~T}$ [30]. This lead to an acquisition time of $12 \mathrm{~min}$ for $734 \mu \mathrm{m}$ in-plane 
resolution and $1 \mathrm{~mm}$ thickness slices. Furthermore, residual motion artifacts were observed despite the use of the « diffusion-weighted whole-body imaging with background body signal suppression » (DWIBS) technique. Another technique employing an alginate mould to limit air-tissue interference that could increase susceptibility artifacts was used to limit motion. Due to this, artifacts and distortion of the low b-values $2 \mathrm{D}$ images $\left(\mathrm{b}=0.1 \mathrm{~s} / \mathrm{mm}^{2}\right)$ were reduced enabling detection of gastric tumors within mouse abdomen at 3T [31]. In our study, to circumvent the respiration motion issue, bipolar gradients containing two identical lobes of opposite signs were added and combined with interleaved multi-shot EPI [32]. This method has already been used for human cardiac diffusion imaging in combination with cardiac triggering and with or without respiration synchronization at clinical magnetic fields [19,33]. The highest b-values used in these previous studies were less than $400 \mathrm{~s} / \mathrm{mm}^{2}$, in order to limit the duration of the bipolar gradients. Due to stronger gradients used for our experiments, the duration of each lobe of the bipolar gradients was as short as $3.5 \mathrm{~ms}$ and b-values higher than $1000 \mathrm{~s} / \mathrm{mm}^{2}$ could be reached. Even if TE was increased by the insertion of a second lobe, free breathing acquisitions were performed without inducing any respiratory motion artifacts on the images. Although the bipolar gradients were applied along the phase direction as it is usually performed in clinics, diffusion gradients could have been applied along another direction or in a combination of different directions. Nevertheless, applying diffusion gradients in the read or slice directions might lead to blurry images, mainly due to the main orientation of the respiration process.

Based on the insertion of the water-selective pulse and the bipolar diffusion gradients, it was possible to acquire $3 \mathrm{D}$ high-resolution images $(182 \times 156 \times 125 \mu \mathrm{m})$ in $8 \mathrm{~min}$. This lead to a precise ADC measurement of healthy parts of the liver, as demonstrated by similar values 
obtained in previous studies $\left(\approx 0.8 \times 10^{-3} \mathrm{~mm}^{2} / \mathrm{s} \quad[27] ; 0.97 \pm 0.06 \times 10^{-3} \mathrm{~mm}^{2} / \mathrm{s} \quad\right.$ [28]; $\left.0.693-0.73 \times 10^{-3} \mathrm{~mm}^{2} / \mathrm{s}[29] ; \approx 1 \times 10^{-3} \mathrm{~mm}^{2} / \mathrm{s}[31] ; 749-811 \times 10^{-6} \mathrm{~mm}^{2} / \mathrm{s}[34]\right)$.

Here is the first study to perform 3D abdominal diffusion imaging to measure ADC of single small liver metastases on small animals at $7 \mathrm{~T}$ without respiration triggering. Wagner et al performed diffusion imaging using a respiratory-gated 2D DW-SE sequence to detect less than $1 \mathrm{~mm}$-diameter hepatic metastases at $7 \mathrm{~T}$ [35]. To do so, a 1h-acquisition time was necessary that could prevent routine application of the sequence. Furthermore, only low bvalues were used to characterize the diffusion at $7 \mathrm{~T}$, which could have hampered the detection of intra-tumoral heterogeneity. In addition, the intraparenchymal injection model differs from the portal vein injection of the cancer cells used in our study. As mentioned by the authors, this injection route is far from the usual metastatic process.

Despite the unique injection of melanoma cells carried out in our study, the liver metastases didn't have similar ADC at the same time points. This might be dependent on the phase in the division cycle in which the cancer cells were at the injection time. This would have influenced the time at which metastasis development started, demonstrating a difference in their physiological states. This was confirmed by the fact that metastases became detectable on conventional T2-like weighted bSSFP images at different time points after injection (data not shown). This is in agreement with a previous study in which the number of brain metastases kept increasing over time after injection [36].

Due to the high resolution of the images, metastases of less than $0,2 \mathrm{~mm}^{3}$ were easily detected with hyperintense signal. The lowest $b$ value used in our study was $200 \mathrm{~s} / \mathrm{mm}^{2}$. Even if b values closer to $50 \mathrm{~s} / \mathrm{mm}^{2}$ showed a great sensitivity of liver metastasis detection, higher bvalues allowed to detect heterogeneities within tumors. Thus, contrarily to T2-weighted 
images that only inform on the locations of the metastases, quantitative information were also obtained. The cores of some metastases had increased diffusivity compared to the edges. Histology on these metastases demonstrated that large edemas were located in the center. Metastases with dense cellularity could thus be distinguished from them through the hyperintense signal on diffusion images, as a consequence of the low diffusivity. The ADC of these two populations were significantly different, which can be of great interest to diagnose accurately benign versus malignant small metastases. To our knowledge, this is the first study to obtain ADC of abdominal metastases in small animals at high magnetic field. The ADC values measured in this study are consistent with previous reports performed on primary tumors: gastric tumor $\mathrm{ADC}=0.6-1.2 \times 10^{-3} \mathrm{~mm}^{2} / \mathrm{s}[31]$, intramuscular liver tumor $\mathrm{ADC}=$ $5-10 \times 10^{-4} \mathrm{~mm}^{2} / \mathrm{s}$ [37], intradermally melanoma xenograft $\mathrm{ADC}=0.53-1 \times 10^{-3} \mathrm{~mm}^{2} / \mathrm{s}[1]$, subcutaneous hepatocellular carcinoma $\mathrm{ADC}=1-1.2 \times 10^{-3} \mathrm{~mm}^{2} / \mathrm{s}[8]$. The hepatic metastases developed in our study had similar ADC values than brain metastases $\left(1.3 \mu \mathrm{m}^{2} / \mathrm{ms}\right)$ induced by breast cancer cells [38]. Finally, the ADC values measured in our study are in the same range as the ones measured on hepatic metastases in humans $\left(1.13 \pm 0.21 \times 10^{-3} \mathrm{~mm}^{2} / \mathrm{s}\right)$ [39], which highlights the possible translation of the sequence to clinic.

The functional information obtained in this study would be of great interest to follow metastasis responses to treatments in small animals and humans. Speck et al developed a SEEPI sequence at $7 \mathrm{~T}$ to image in a single-shot the entire human brain [40], highlighting the potential translation to diffusion imaging through the improvement in materials/equipments and correction methods. For human abdominal imaging, single-sided diffusion gradients can be used to reduce the influence of coherently moving spins by shortening diffusion time and limit signal attenuation, as already demonstrated on excised pig spinal cord [41]. Even though 
high $b$ values couldn't be reached, the sensitivity to respiration motion could be decreased in vivo. Other techniques could be developed to obtain diffusion images using the 3D SE-EPI sequence without motion artifacts, like acquiring the data with radial or spiral [11] trajectories.

In conclusion, this study focused on the development of a 3D diffusion-weighted sequence in order to suppress fat signal and respiration-related artifacts. Consequently, this sequence could be further used at high magnetic field on any part fo the small animal body. Liver metastases were accurately detected and characterized. This would be of great interest for fundamental research on the metastatic process and for anti-cancer drug development.

\section{ACKNOWLEGMENTS}

This work was supported by a public grant, Translational Research and Advanced Imaging Laboratory, which is part of the French National Research Agency's Investments for the Future Program ("NewFISP"; ANR- 10-LABX-57) and by the Centre National de la Recherche Scientifique (CNRS). 


\section{REFERENCES}

[1] Hompland T, Ellingsen C, Galappathi K, Rofstad EK (2014) DW-MRI in assessment of the hypoxic fraction, interstitial fluid pressure, and metastatic propensity of melanoma xenografts. BMC Cancer 14:92.

[2] Panagiotaki E, Walker-Samuel S, Siow B, Johnson SP, Rajkumar V, Pedley RB, Lythgoe MF, Alexander DC (2014) Noninvasive Quantification of Solid Tumor Microstructure Using VERDICT MRI. Cancer Res 74(7):1902-1912.

[3] Li X, Jiang H, Niu J, Zheng Y (2014) Correlation of ADC value with pathologic indexes in colorectal tumor homografts in Balb/c mouse. Chin J Cancer Res 26(4):444-450.

[4] Yun BL, Cho N, Li M, Jang MH, Park SY, Kang HC, Kim B, Song IC, Moon WK (2014) Intratumoral Heterogeneity of Breast Cancer Xenograft Models: Texture Analysis of Diffusion-Weighted MR Imaging. Korean J Radiol 15(5):591-604.

[5] Squillaci E, Bolacchi F, Altobelli S, Franceschini L, Bergamini A, Cantonetti M, Simonetti G (2014) Pre-treatment staging of multiple myeloma patients: comparison of whole-body diffusion weighted imaging with whole-body T1-weighted contrast-enhanced imaging. Acta Radiol. doi:10.1177/0284185114538792.

[6] Wang HJ, Pui MH, Guo Y, Li SR, Liu MJ, Guan J, Zhang XL, Feng Y (2014) Value of normalized apparent diffusion coefficient for estimating histological grade of vesical urothelial carcinoma. Clin Radiol 69:727-731.

[7] Roth Y, Tichler T, Kostenich G, Ruiz-Cabello J, Maier SE, Cohen JS, Orenstein A, Mardor Y (2004) High-b-Value Diffusion-weighted MR Imaging for Pretreatment Prediction and Early Monitoring of Tumor Response to Therapy in Mice. Radiol 232:685-692. 
[8] Zhao YL, Guo QQ, Yang GG, Wang QD (2014) Early changes in apparent diffusion coefficient as an indicator of response to sorafenib in hepatocellular carcinoma. J Zhejiang Univ-Sci B (Biomed \& Biotechnol) 15(8):713-719.

[9] Benndorf M, Schelhorn J, Dietzel M, Kaiser WA, Baltzer PAT (2012) Diffusion weighted imaging of liver lesions suspect for metastases: Apparent diffusion coefficient (ADC) values and lesion contrast are independent from Gd-EOB-DTPA administration. Eur J Radiol 81:e849-e853.

[10] Guilfoyle DN, Gerum S, Hrabe J (2011) Murine diffusion imaging using snapshot interleaved EPI acquisition at 7 T. J Neurosci Methods 199:10-14.

[11] Van de Looij Y, Mauconduit F, Beaumont M, Valable S, Farion R, Francony G, Payen JF, Lahrech H (2011) Diffusion tensor imaging of diffuse axonal injury in a rat brain trauma model. NMR Biomed 25:93-103.

[12] Xue R, Sawada M, Goto S, Hurn PD, Traystman RJ, Van Zijl PCM, Mori S (2001) Rapid Three-Dimensional Diffusion MRI Facilitates the Study of Acute Stroke in Mice. Magn Reson Med 46:183-188.

[13] Moffat BA, Chenevert TL, Meyer CR, Mckeevery PE, Hall DE, Hoff BA, Johnson TD, Rehemtulla A, Ross BD (2006) The Functional Diffusion Map: An Imaging Biomarker for the Early Prediction of Cancer Treatment Outcome. Neoplasia 8:259-267.

[14] Harsan LA, Paul D, Schnell S, Kreher BW, Hennig J, Staiger JF, von Elverfeldt D (2010) In vivo diffusion tensor magnetic resonance y imaging and fiber tracking of the mouse brain. NMR Biomed 23:884-896.

[15] Aggarwal M, Mori S, Shimogori T, Blackshaw S, Zhang J (2010) Three-Dimensional Diffusion Tensor Microimaging for Anatomical Characterization of the Mouse Brain. Magn Reson Med 64:249-261. 
[16] Padhani AR, Liu G, Mu-Koh D, Chenevert TL, Thoeny HC, Takahara T, Dzik-Jurasz A, Ross BD, Van Cauteren M, Collins D, et al (2009) Diffusion-Weighted Magnetic Resonance Imaging as a Cancer Biomarker: Consensus and Recommendations. Neoplasia 11:102-125.

[17] Morris VL, MacDonald IC, Koop S, Schmidt EE, Chambers AF, Groom AC (1993) Early interactions of cancer cells with the microvasculature in mouse liver and muscle during hematogenous metastasis: videomicroscopic analysis. Clin. Exp. Metastasis 11:377-390.

[18] Kornaat PR, Doornbos J, van der Molen AJ, Kloppenburg M, Nelissen RG, PCW Hogendoorn, Bloem JL (2004) Magnetic Resonance Imaging of Knee Cartilage Using a Water Selective Balanced Steady-State Free Precession Sequence. J. Magn. Reson. Imaging 20:850 856.

[19] Gamper U, Boesiger P, Kozerke S (2007) Diffusion Imaging of the In Vivo Heart Using Spin Echoes-Considerations on Bulk Motion Sensitivity. Magn Reson Med 57:331-337.

[20] Koh DM, Collins DJ (2007) Diffusion-Weighted MRI in the Body: Applications and Challenges in Oncology. Am J Roentgenol 188:1622-1635.

[21] Thoeny HC, Ross BD (2010) Predicting and Monitoring Cancer Treatment Response with Diffusion-Weighted MRI. J. Magn. Reson. Imaging 32:2-16.

[22] Alexander AL, Tsuruda JS, Parker DL (1997) Elimination of Eddy Current Artifacts in Diffusion-Weighted Echo-Planar Images: The Use of Bipolar Gradients. Magn Reson Med 38:1016-1021.

[23] Buonocore MH, Zhu DC (2001) Image-Based Ghost Correction for Interleaved EPI. Magn Reson Med 45:96-108.

[24] Larson AC, Kellman P, Arai A, Hirsch GA, McVeigh E, Li D, Simonetti OP (2005) Preliminary Investigation of Respiratory Self-Gating for Free-Breathing Segmented Cine MRI. Magn Reson Med 53:159-168. 
[25] Ribot EJ, Duriez TJ, Trotier AJ, Thiaudiere E, Franconi JM, Miraux S (2014) Self-gated bSSFP sequences to detect iron-labeled cancer cells and/or metastases in vivo in mouse liver at 7 Tesla. J Magn Reson Imaging. doi: 10.1002/jmri.24688.

[26] Yuan J, Madore B, Panych LP (2011) Fat-water selective excitation in balanced steadystate free precession using short spatial-spectral RF pulses. J Magn Reson 208:219-224.

[27] Zhou IY, Gao DS, Chow AM, Fan S, Cheung MM, Ling C, Liu X, Cao P, Guo H, Man K, et al (2014) Effect of Diffusion Time on Liver DWI: An Experimental Study of Normal and Fibrotic Livers. Magn Reson Med 72:1389-1396.

[28] Chow AM, Gao DS, Fan SJ, Qiao Z, Lee FY, Yang J, Man K, Wu EX (2012) Liver Fibrosis: An Intravoxel Incoherent Motion (IVIM) Study. J Magn Reson Imaging 36:159167.

[29] Lee Y, Kim H (2014) Assessment of Diffusion Tensor MR Imaging (DTI) in Liver Fibrosis with Minimal Confounding Effect of Hepatic Steatosis. Magn Reson Med. doi 10.1002/mrm.25253.

[30] Lee HJ, Luci JJ, Tantawy MN, Lee H, Nam KT, Peterson TE, Price RR (2013) Detecting peritoneal dissemination of ovarian cancer in mice by DWIBS. Magn Reson Imaging 31:227234.

[31] Sun J, Zhang XP, Li XT, Tang L, Cui Y, Zhang XY, Sun YS (2014) Applicable apparent diffusion coefficient of an orthotopic mouse model of gastric cancer by improved clinical MRI diffusion weighted imaging. Sci Rep 4:6072.

[32] Hennel F. Image-Based Reduction of Artifacts in Multishot Echo-Planar Imaging (1998) J Magn Reson 134:206-213

[33] Dou J, Reese TG, Tseng WYI, Wedeen VJ (2002) Cardiac Diffusion MRI Without Motion Effects. Magn Reson Med 48:105-114. 
[34] Anderson SW, Soto JA, Milch HN, Ozonoff A, O’Brien M, Hamilton JA, Jara HJ (2011)

Effect of Disease Progression on Liver Apparent Diffusion Coefficient Values in a Murine Model of NASH at 11.7 Tesla MRI. J Magn Reson Imaging 33:882-888.

[35] Wagner M, Maggiori L, Ronot M, Paradis V, Vilgrain V, Panis Y, Van Beers BE. (2013)

Diffusion-weighted and T2-weighted MR imaging for colorectal liver metastases detection in a rat model at $7 \mathrm{~T}$ : a comparative study using histological examination as reference. Eur Radiol 23:2156-2164.

[36] Perera M, Ribot EJ, Percy DB, McFadden C, Simedrea C, Palmieri D, Chambers AF, Foster PJ (2012) In Vivo Magnetic Resonance Imaging for Investigating the Development and Distribution of Experimental Brain Metastases due to Breast Cancer. Trans Oncol 5(3):217225.

[37] Radermacher KA, Magat J, Bouzin C, Laurent S, Dresselaers T, Himmelreich U, Boutry S, Mahieu I, Vander Elst L, Feron O, et al (2012) Multimodal assessment of early tumor response to chemotherapy: comparison between diffusion-weighted MRI, 1H-MR spectroscopy of choline and USPIO particles targeted at cell death. NMR Biomed 25:514522.

[38] Budde MD, Gold E, Jordan EK, Frank JA (2012) Differential microstructure and physiology of brain and bone metastases in a rat breast cancer model by diffusion and dynamic contrast enhanced MRI. Clin Exp Metastasis 29:51-62.

[39] Sun XJ, Quan XY, Huang FH, Xu YK (2005) Quantitative evaluation of diffusionweighted magnetic resonance imaging of focal hepatic lesions. World J Gastroenterol 11(41):6535-6537.

[40] Speck O, Stadler J, Zaitsev M (2008) High resolution single-shot EPI at 7T. Magn Reson Mater Phy 21:73-86. 
[41] Freidlin RZ, Kakareka JW, Pohida TJ, Komlosh ME, Basser PJ (2012) A spin echo sequence with a single-sided bipolar diffusion gradient pulse to obtain snapshot diffusion weighted images in moving media. J Magn Reson 221:24-31. 


\begin{tabular}{|c|c|c|c|c|}
\hline Parameters & Native & FatSat + Trig & WS \pm Trig & WS + Bipolar \\
\hline FOV & $35 \times 30 \times 16 \mathrm{~mm}$ & $35 \times 30 \times 16 \mathrm{~mm}$ & $35 \times 30 \times 16 \mathrm{~mm}$ & $35 \times 30 \times 16 \mathrm{~mm}$ \\
\hline Matrix & $192 \times 192 \times 128$ & $192 \times 192 \times 128$ & $192 \times 192 \times 128$ & $192 \times 192 \times 128$ \\
\hline TEeff/TR & $31.7 / 1000 \mathrm{~ms}$ & $31.7 / 1000 \mathrm{~ms}$ & $32.5 / 1000 \mathrm{~ms}$ & $39.2 / 1000 \mathrm{~ms}$ \\
\hline rBW; echoes/TR & 2365Hz/pixel; 48 & 2365Hz/pixel; 48 & $2365 \mathrm{~Hz} /$ pixel; 48 & $2365 \mathrm{~Hz} /$ pixel; 48 \\
\hline $\begin{array}{l}\text { Fat Suppression } \\
\text { module }\end{array}$ & None & Fat Saturation & $\begin{array}{l}\text { Water-Selective } \\
\text { Binomial pulse }\end{array}$ & $\begin{array}{l}\text { Water-Selective } \\
\text { Binomial pulse }\end{array}$ \\
\hline $\begin{array}{l}\text { Respiration } \\
\text { Triggering }\end{array}$ & No & Yes & Yes / No & No \\
\hline $\begin{array}{l}\text { Diffusion } \\
\text { gradients }\end{array}$ & Monopolar & Monopolar & Monopolar & Bipolar \\
\hline$\delta / \Delta$ & $3.5 / 5.9 \mathrm{~ms}$ & $3.5 / 5.9 \mathrm{~ms}$ & $3.5 / 5.9 \mathrm{~ms}$ & $3.5 \mathrm{~ms}$ \\
\hline Acq Time & $8 \min 32 s$ & $\approx 10 \mathrm{~min} 14 \mathrm{~s}$ & $\begin{array}{c}\approx 10 \min 14 \mathrm{~s} / \\
8 \mathrm{~min} 32 \mathrm{~s}\end{array}$ & $8 \min 32 s$ \\
\hline
\end{tabular}

Table 1: Parameters of the several sequences performed. " Native " sequence is a conventional diffusion-weighted SE-EPI sequence with the Stejskal-Tanner module and modified into 3D. "FatSat » sequence is a Native DW sequence with the vendor fat suppression module. "WS " indicates that the usual $90^{\circ}$ radiofrequency pulse has been replaced by a water-selective excitation binomial pulse. "Bipolar » indicates that bipolar diffusion gradients have been employed instead of the usual monopolar gradients. " Trig » indicates that respiration triggering was used. 


\begin{tabular}{|c|c|c|c|c|c|}
\hline & Native & FatSat + Trig & wS & WS + Trig & WS + Bipolar \\
\hline Fat SNR & $10.7 \pm 0.6$ & $4.7 \pm 0.5$ & $3.6 \pm 0.9$ & $4 \pm 0.6$ & $4 \pm 0.6$ \\
\hline Sharpness & $0.6 \pm 0.1$ & $2.9 \pm 0.8$ & $0.5 \pm 0.1$ & $2 \pm 0.1$ & $5.6 \pm 0.8$ \\
\hline St Dev Noise & $639 \pm 56$ & $444 \pm 34.2$ & $627.8 \pm 50.8$ & $417.1 \pm 24.2$ & $240.2 \pm 36.8$ \\
\hline RGI & $77 \pm 3.4$ & $60.3 \pm 2.4$ & $61.4 \pm 4.2$ & $55.3 \pm 5.6$ & $34.2 \pm 9$ \\
\hline
\end{tabular}

Table 2: Fat SNR, Sharpness, Standard Deviation of the Noise and Relative Ghost Intensity (RGI) measured on healthy mouse abdomen with the different sequences used. Fat SNR was significant higher on Native images than on FatSat+Trig images $(p=0.003)$ and the WS images $(p=0.014, p=0.009, p=0.009$ with WS, WS+Trig and WS+Bipolar, respectively).

Sharpness and St Dev Noise measurements on WS and WS+Trig images were significantly different $(p=0.0016$ and $p=0.016$, respectively). Furthermore, sharpness and St Dev Noise measurements on WS+Trig and WS+Bipolar images were significantly different $(\mathrm{p}=0.039$ and $\mathrm{p}=0.0015$, respectively).

RGI was significantly higher on Native images than on FatSat+Trig images $(p=0.037)$ and the WS images ( $p=0.03, p=0.048, p=0.02$ with WS, WS+Trig and WS+Bipolar, respectively). 


\begin{tabular}{|c|c|c|c|c|}
\hline & Native & FatSat + Trig & WS + Trig & WS + Bipolar \\
\hline $\begin{array}{l}\text { Presence of fat } \\
\text { signal }\end{array}$ & $2.25 \pm 1$ & $3.5 \pm 0.5$ & $3.8 \pm 0.4$ & $4.6 \pm 0.7^{*}$ \\
\hline $\begin{array}{l}\text { Presence of } \\
\text { motion artifact }\end{array}$ & $1.9 \pm 1.1$ & $3.1 \pm 0.6$ & $3.5 \pm 0.6$ & $4.4 \pm 0.5 \#$ \\
\hline $\begin{array}{l}\text { Presence of } \\
\text { Ghosts }\end{array}$ & $2 \pm 1.2$ & $3.3 \pm 0.9$ & $2.8 \pm 1$ & $4.4 \pm 0.7^{*}$ \\
\hline Overall Quality & $1.9 \pm 1.1$ & $2.9 \pm 0.8$ & $3.3 \pm 0.5$ & $4.8 \pm 0.5 \#$ \\
\hline
\end{tabular}

Table 3: Mean scores of the image qualities measured by two readers. Every WS+Bipolar scores were significantly different from the ones of the other sequences ${ }^{*}$ and \# represent $\mathrm{p}<0.05$ and $\mathrm{p}<0.01$, respectively)

\begin{tabular}{|c|c|c|c|c|c|c|}
\hline & $\mathbf{b 2 0 0}$ & $\mathbf{b 4 0 0}$ & $\mathbf{b 6 0 0}$ & $\mathbf{b 8 0 0}$ & $\mathbf{b 1 0 0 0}$ & $\mathbf{b 1 1 0 0}$ \\
\hline Core & $3.29 \pm 0.03$ & $2.99 \pm 0.03$ & $2.41 \pm 0.06$ & $1.94 \pm 0.03$ & $1.21 \pm 0.02$ & $1 \pm 0.11$ \\
\hline Edge & $3.34 \pm 0.09$ & $3.23 \pm 0.04$ & $2.94 \pm 0.08$ & $2.47 \pm 0.03$ & $2.22 \pm 0.04$ & $2.02 \pm 0.06$ \\
\hline Top & $2.78 \pm 0.05$ & $2.48 \pm 0.02$ & $2.34 \pm 0.06$ & $2.07 \pm 0.12$ & $1.74 \pm 0.32$ & $1.77 \pm 0.08$ \\
\hline Bottom & $2.71 \pm 0.03$ & $2.52 \pm 0.04$ & $2.5 \pm 0.05$ & $2.39 \pm 0.07$ & $2.37 \pm 0.04$ & $2.33 \pm 0.08$ \\
\hline
\end{tabular}

Table 4 4: $\ln (\mathrm{SNR})$ of two different areas in a metastasis and between two independent metastases as a function of $\mathbf{b}$ values. The core and the edge $\ln (\mathrm{SNR})$ values were measured on the liver metastasis shown in Figure 5a,b,c. The $\ln (\mathrm{SNR})$ values of two typical liver metastases were measured in the ones indicated by the dashed arrow and the arrowhead (noted Top and Bottom, respectively) in Figure 5d,e,f. 


\begin{tabular}{|c|c|c|c|c|c|c|c|}
\hline Met ID & $\begin{array}{c}\text { ADC } \\
\left(\mathbf{s} / \mathbf{m m}^{2}\right)\end{array}$ & Met ID & $\begin{array}{c}\text { ADC } \\
\left(\mathbf{s} / \mathbf{m m}^{2}\right)\end{array}$ & Met ID & $\begin{array}{c}\text { ADC } \\
\left(\mathbf{s} / \mathbf{m m}^{2}\right)\end{array}$ & Met ID & $\begin{array}{c}\text { ADC } \\
\left(\mathbf{s} / \mathbf{m m}^{2}\right)\end{array}$ \\
\hline 1 & $1,17 \pm 0.08$ & 6 & $0,4 \pm 0$ & 11 & $1,6 \pm 0.12$ & 16 & $1,7 \pm 0.12$ \\
\hline 2 & $0,38 \pm 0.06$ & 7 & $0,5 \pm 0.1$ & 12 & $1,4 \pm 0.12$ & 17 & $1,9 \pm 0.06$ \\
\hline 3 & $0,2 \pm 0$ & 8 & $0,4 \pm 0.06$ & 13 & $1,2 \pm 0.06$ & 18 & $2 \pm 0.15$ \\
\hline 4 & $0,7 \pm 0.15$ & 9 & $2,65 \pm 0.15$ & 14 & $1,6 \pm 0.1$ & 19 & $2,2 \pm 0$ \\
\hline 5 & $0,8 \pm 0.15$ & 10 & $1,6 \pm 0.6$ & 15 & $1,7 \pm 0.06$ & 20 & $2,1 \pm 0.06$ \\
\hline
\end{tabular}

Supplementary Table 1 : ADC of 20 metastases detected in several mice 


\section{FIGURE LEGENDS}

Figure 1: Diffusion-weighted SE-EPI sequence containing three modules: the binomial excitation pulse, the diffusion and the EPI module. Five square pulses were combined to form a water-selective binomial $90^{\circ}$ excitation pulse. Meanwhile, the slice selection gradient was removed. Bipolar diffusion gradients were added on each side of the $180^{\circ}$ refocusing $\mathrm{RF}$ pulse. Four acquisition shots were used. "S" refers to Spoiler gradients. Diffusion gradient durations $(\delta)$ was $3.5 \mathrm{~ms}$. « Gd » indicates diffusion gradient intensity.

Figure 2: Axial (a,c) and coronal $(b, d)$ diffusion images $\left(b=100 \mathrm{~s} / \mathrm{mm}^{2}\right)$ extracted from 3D data sets acquired with either a Fat Saturation $(a, b)$ or the water-selective binomial pulse (c,d) module. The arrows point at areas where fat signal was not efficiently attenuated. The arrowhead points at an area where water protons were saturated by the fat suppression module due to a low magnetic field homogeneity. Scale bars represent $5 \mathrm{~mm}$.

Figure 3: Axial $(a, b, c)$ and coronal $(d, e, f)$ diffusion images $\left(b=600 \mathrm{~s} / \mathrm{mm}^{2}\right)$ extracted from 3D data sets acquired with the water-selective binomial pulse only (a,d) or in combination with either a respiration trig $(b, e)$ or bipolar diffusion gradients $(c, f)$. In the case of a,b,d,e, monopolar diffusion gradients were used. The arrow points out motion artifact. Scale bars represent $5 \mathrm{~mm}$.

Figure 4: Axial (a,b,c) and coronal (d,e,f) diffusion images extracted from 3D data sets of a healthy mouse acquired with the water-selective binomial pulse in combination with bipolar diffusion gradients at increasing intensities : $b=200 \mathrm{~s} / \mathrm{mm}^{2}(a, d), b=600 \mathrm{~s} / \mathrm{mm}^{2}(b, e)$ and $b=1100 \mathrm{~s} / \mathrm{mm}^{2}(\mathrm{c}, \mathrm{f})$. 
Figure 5: Coronal diffusion images extracted from 3D data sets acquired with the waterselective binomial pulse in combination with bipolar diffusion gradients at increasing intensities on two independent mice bearing liver metastases. Images were acquired at $b=200 \mathrm{~s} / \mathrm{mm}^{2}(\mathrm{a}, \mathrm{d}), \mathrm{b}=600 \mathrm{~s} / \mathrm{mm}^{2}(\mathrm{~b}, \mathrm{e})$ and $\mathrm{b}=1100 \mathrm{~s} / \mathrm{mm}^{2}(\mathrm{c}, \mathrm{f})$. The arrow in (a) points at a metastasis which core has a higher diffusivity than the periphery at high b values $(b, c)$. The dashed arrow and the arrowhead in (d) point at two metastases that had similar hyperintense signals at low b values (d) but different intensities at $b=1100 \mathrm{~s} / \mathrm{mm}^{2}$ (f). Scale bars represent $5 \mathrm{~mm}$.

Figure 6: Axial diffusion images extracted from the same 3D data sets as in Figure 5 and the corresponding histology slides. The inserts in (a) and (c) are magnifications of the areas where metastases were present (arrows). (b) and (d) are histology pictures of two main types of metastasis developing in the mouse liver: one filled with edema (arrow in (a)), and one with dense cellularity (arrow in (b)). Scale bars represent $0.5 \mathrm{~mm}$.

Supplementary Figure 1: Excitation profile of 12321 pulse at 7T. The blue and the green line represent the water and the fat resonance frequencies, respectively. 
Figure 1

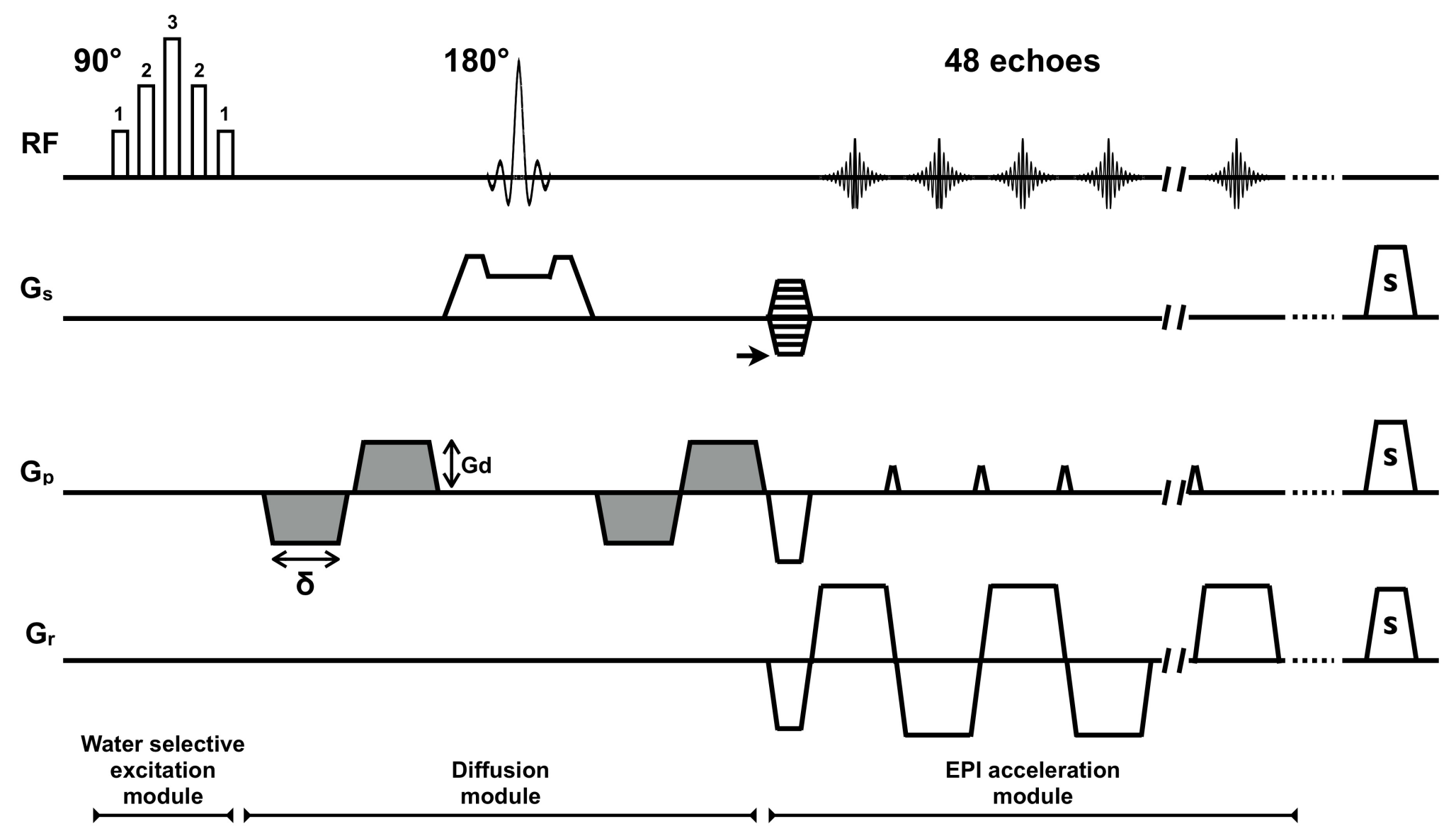


Figure 2
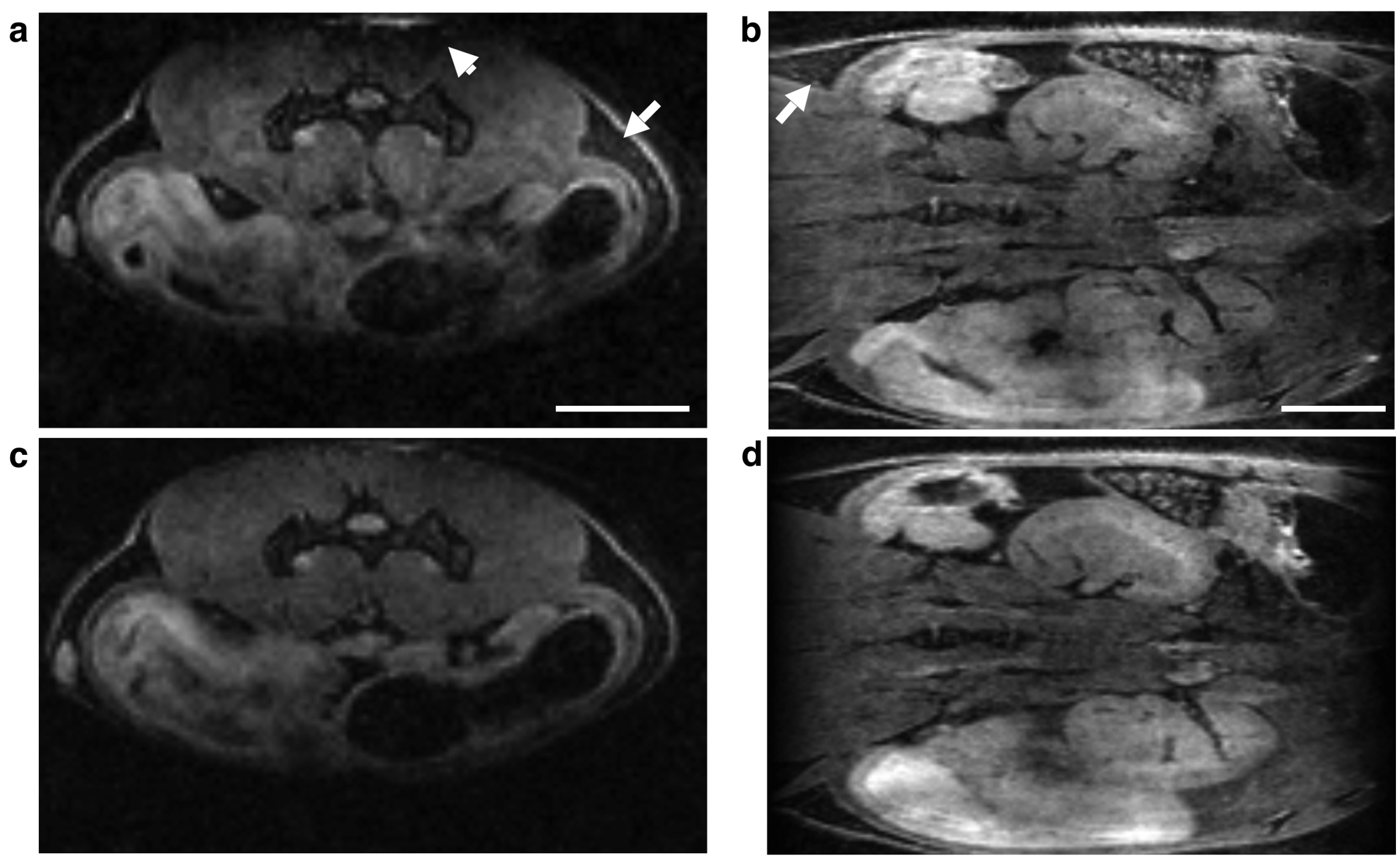
Figure 3

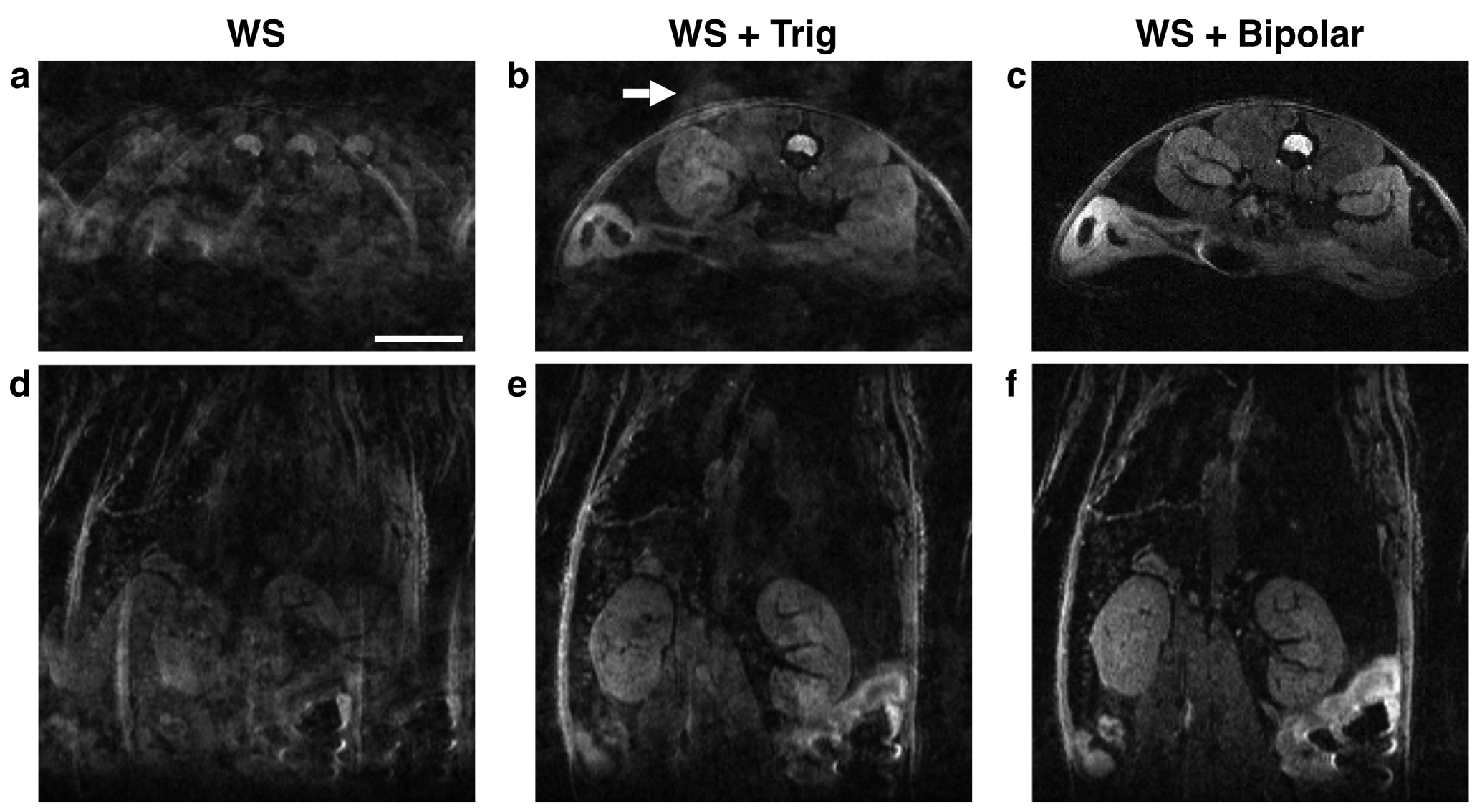


Figure 4

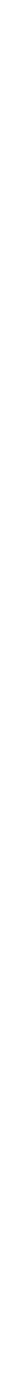


Figure 5

b200

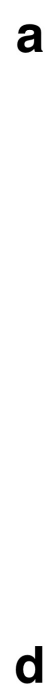

a
d
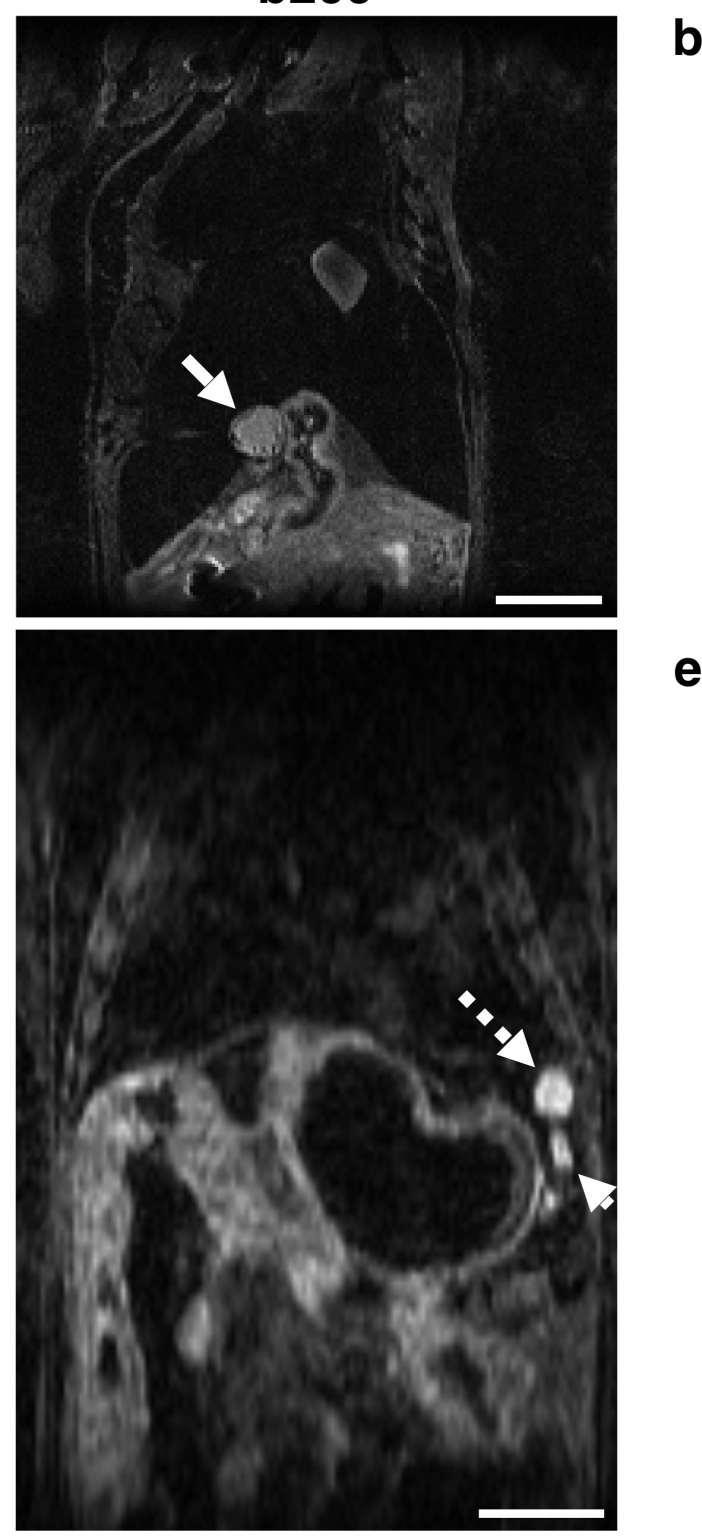

b600

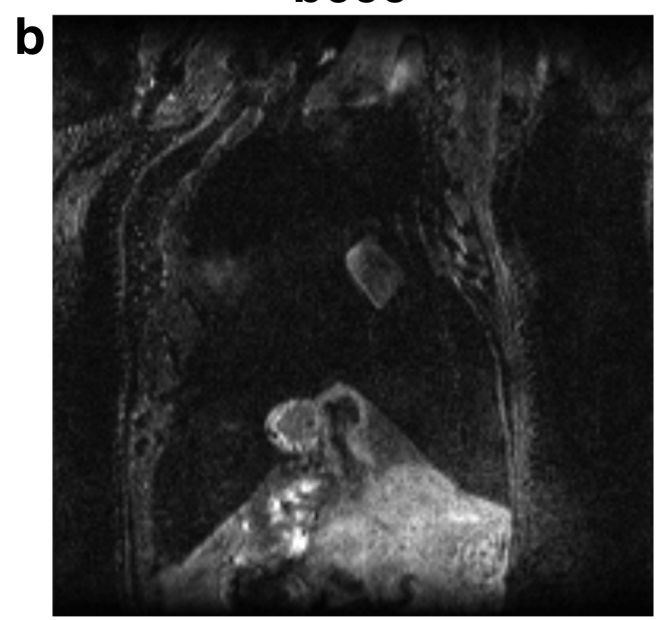

e

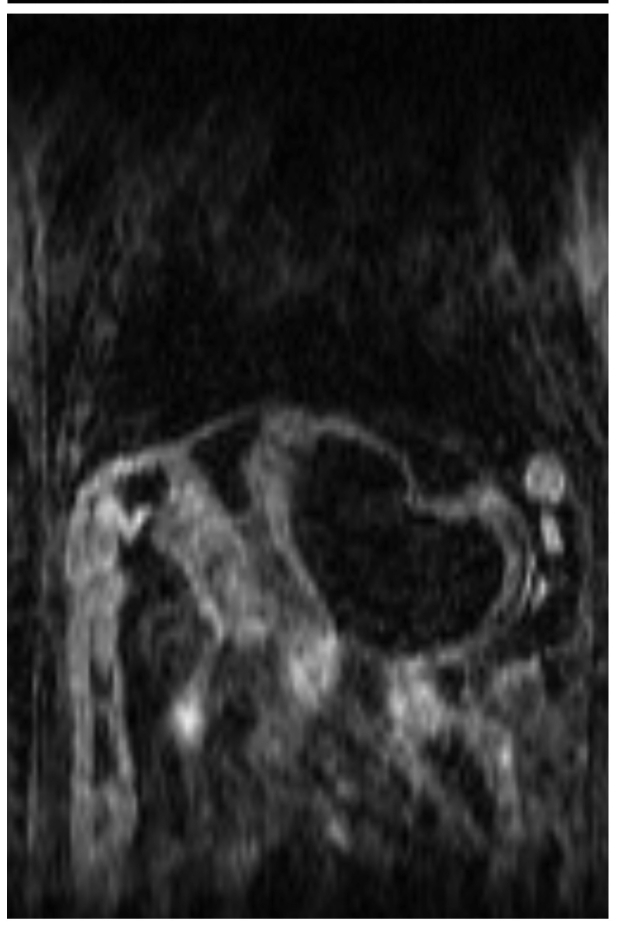

b1100

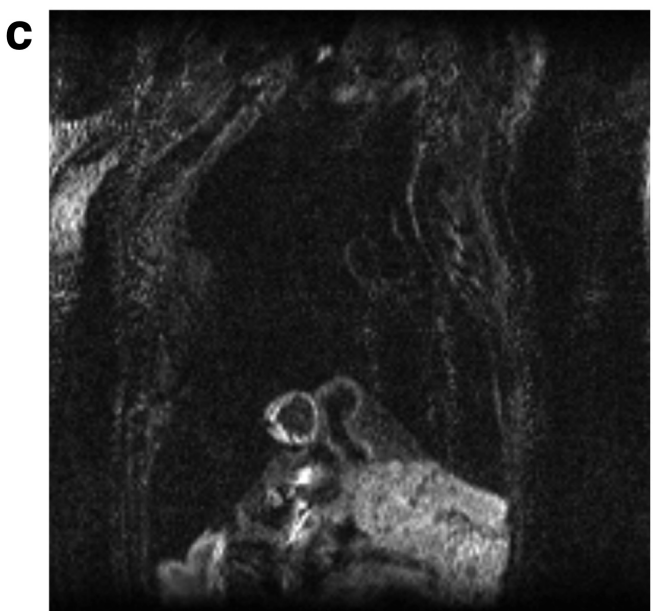

f

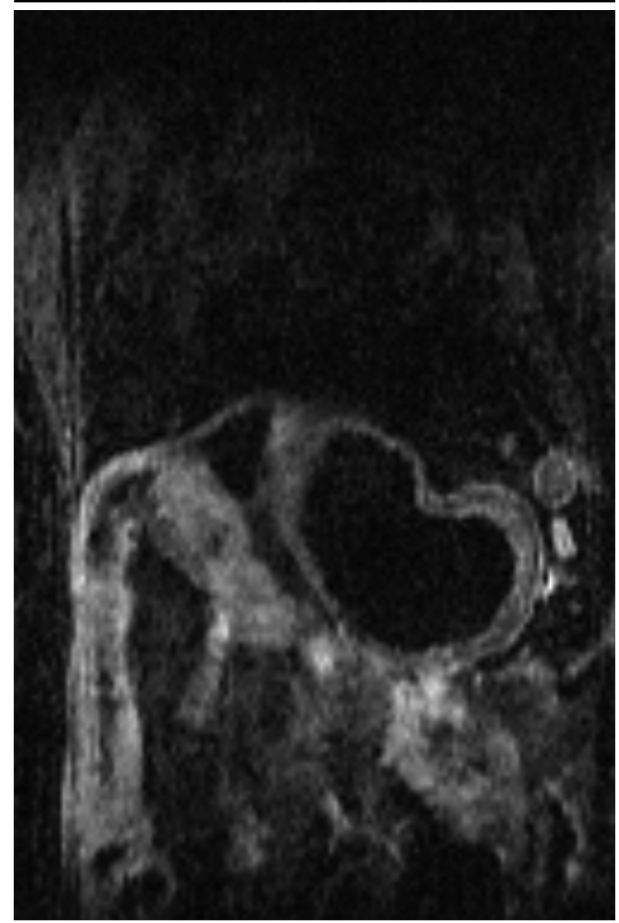


Figure 6
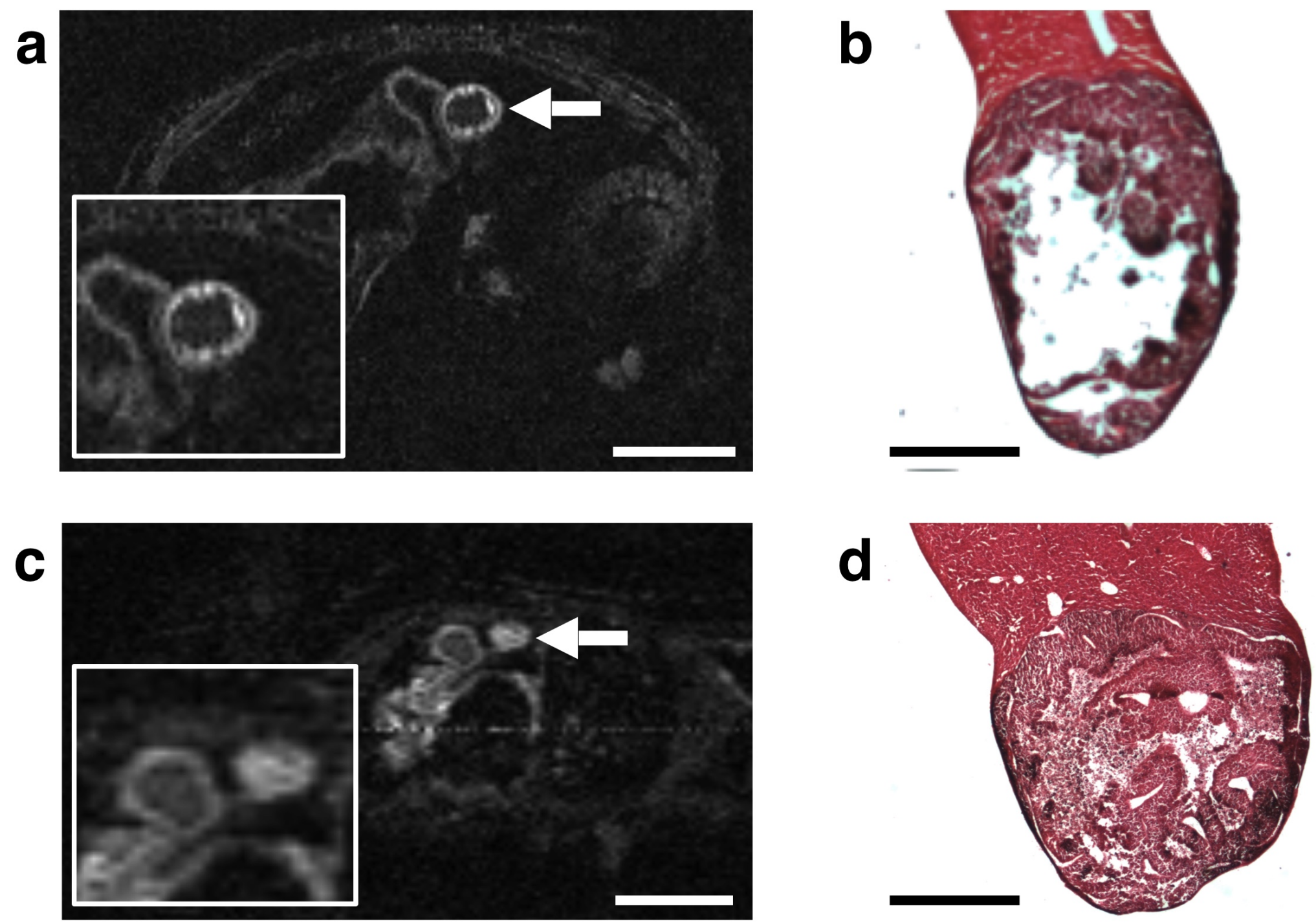


\section{$1(x) 2(x) 3(x) 2(x) 1(x)$}

\section{Supp Mat}

\section{Water}

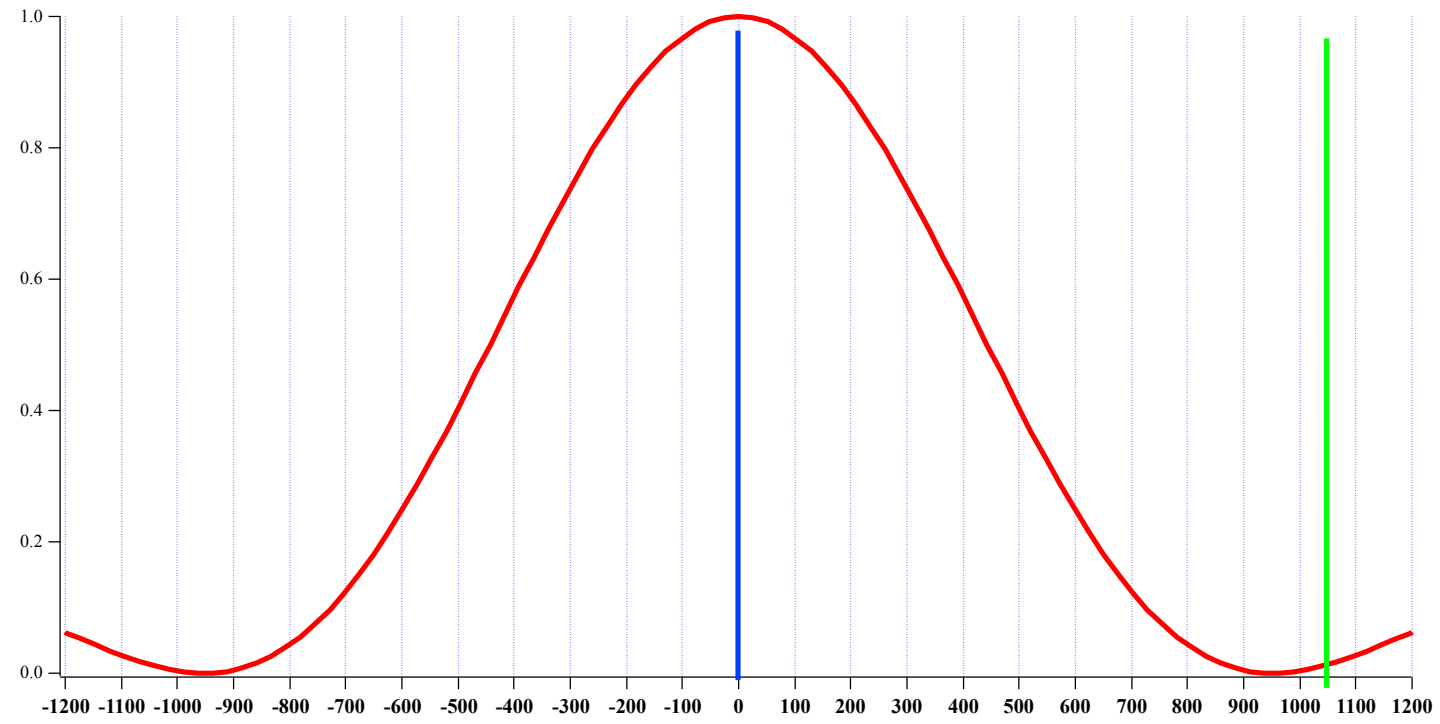

